\title{
Mean Current Profile over Rippled-Beds in the Presence of Non-Breaking Waves and Analysis of Its Influencing Factors
}

\author{
Chunye Hu, Jialing Hao * and Zhen Liu
}

check for updates

Citation: Hu, C.; Hao, J.; Liu, Z. Mean Current Profile over

Rippled-Beds in the Presence of Non-Breaking Waves and Analysis of Its Influencing Factors. J. Mar. Sci. Eng. 2021, 9, 986. https://doi.org/ 10.3390/jmse9090986

Academic Editor: Alvise Benetazzo

Received: 12 August 2021

Accepted: 4 September 2021

Published: 8 September 2021

Publisher's Note: MDPI stays neutral with regard to jurisdictional claims in published maps and institutional affiliations.

Copyright: (c) 2021 by the authors. Licensee MDPI, Basel, Switzerland. This article is an open access article distributed under the terms and conditions of the Creative Commons Attribution (CC BY) license (https:/ / creativecommons.org/licenses/by/ $4.0 /)$.
College of Harbor, Coastal and Offshore Engineering, Hohai University, Nanjing 210098, China; 191303030005@hhu.edu.cn (C.H.); 191303030007@hhu.edu.cn (Z.L.)

* Correspondence: jialingh@hhu.edu.cn

Abstract: Classical eddy viscosity model deviates from the actual mean current profiles, when calculating the mean current profiles over rippled-beds in the presence of non-breaking waves, owing to the neglect of the enhancement of the wave boundary layer thickness by ripples and the wave-induced shear stress (the radiation stress and the wave Reynolds stress). Considering these shortcomings, a semi-empirical one-dimensional vertical (1DV) model is presented in this study. The present model was obtained using the two-dimensional Navier-Stokes equations and eddy viscosity assumptions, which differ from those of previous researchers, while a top-to-bottom sequence was adopted to calculate the mean current profiles. Empirical formulae were derived from the laboratory measurements and used in the present model to accurately predict the wave boundary layer thickness and bed roughness. The present model is in satisfactory agreement with the data from laboratory experiments. The factors influencing the mean current profiles were analyzed also. The wave-induced second-order shear stresses were found to be the principal reason for the deviations of the mean current profiles in the near-surface layer; as the influencing factors of wave-induced shear stress, the intensity of the wave relative to the current, the angle between the wave and current, and the size of ripples can also have a non-negligible effect on the mean current profiles.

Keywords: one-dimensional vertical model; rippled-bed; mean current profile; laboratory measurements; wave-induced shear stress

\section{Introduction}

Fluid motion in combined wave and current conditions is a predominant dynamic driving force of sediment movement in estuarine and coastal areas [1,2]. The wave boundary layer (WBL) is a thin layer where waves, currents, and the bed interact, and the fluid motion within the layer governs sediment resuspension, transport, and the evolution of the bed forms [3]. Therefore, the study of the hydrodynamic characteristics near the bottom in combined wave-current conditions is of great significance for the study of sediment transport; moreover, the shifting of coastline and beach profile evolution has received wide attention from researchers [4-6].

Bed forms and bed roughness have significant effects on bed shear stress, flow structure and sediment concentration in the vicinity of the bed. Flat beds and rippled beds are two common bed forms in combined wave-current flows, and they transform into each other under different dynamic conditions. Ripples appear when dynamic conditions are relatively weaker, and these ripples will be eroded with increased dynamics, resulting in the formation of flat beds, which present a high-intensity sheet flow [7]. Physical bed roughness, $k_{s}$ (equivalent Nikuradse roughness or briefly the hydraulic roughness) is directly defined as the roughness, which is determined from the structure of a purely steady flow over the bed [8]. In Van Rijn [9], $k_{s}$ is determined by fitting a logarithmic distribution to the near-bed flow velocities measured under current alone conditions, and the values of $k_{s}$ were found to be approximately 3-7 times the ripple height. The presence of waves leads to an intensified near-bottom turbulence effect, which can be characterized by introducing an 
"apparent" bed roughness, $k_{a}$; this can be exhibited by the current velocity profile outside the wave boundary layer [10]. Apparent bed roughness is similar to an enhanced physical bed roughness. The existence of such enhanced roughness was confirmed in several prior studies [10-13].

Laboratory experiments are the primary means of studying hydrodynamic properties and sediment transport within and outside the WBL; however, the data provided by laboratory experimental measurements are limited and need to be supplemented by mathematical models. In recent decades, many one-dimensional vertical (1DV) wave-current boundary layer models have been developed, and these models can be classified into theoretical and numerical models. Theoretical models, also called zero-equation models or eddy viscosity models, use assumed eddy viscosity to close the fluid momentum equation, including models that use time-invariant eddy viscosities and time-variant eddy viscosities. Models using time-invariant eddy viscosities such as Grant and Madsen [14] (hereinafter GM model), Christoffersen and Jonsson [15] (hereinafter CJ model), Styles and Glenn [16,17] (hereinafter SG2000 and SG2017 model), and You [18] (hereinafter You model) and models using time-variant eddy viscosities such as Trowbridge and Madsen [19], and Foster et al. [20]. Time-variant eddy viscosity models allow for manifold vertical modes that simulate more realistic flows in association with real waves. However, the above two models did not investigate the combined flow conditions because of the assumption of the dominance of wave on current [21]. Numerical models include one-equation and two-equation models. One-equation models, also called mixing length models, use the turbulence kinetic energy and dynamic mixing length to represent the eddy viscosity, as in Davies et al. [22], and Soulsby et al. [23]. Two-equation models, including k- $\varepsilon$ models and $\mathrm{k}-\omega$ models, use the turbulent kinetic energy and turbulent kinetic energy dissipation rate to represent the eddy viscosity, as in [24-27]. Among these, [27] used the k- $\varepsilon$ model to study the characteristics of hydrodynamics and sediments in flat beds and rippled-beds, and proposed toe-shaped wave eddy viscosities based on the results of the 1DV model.

To study the hydrodynamic characteristics in a combined wave-current flow, it is simpler to use a zero-equation model to close the fluid momentum equation because the one-equation and two-equation models require complex iterations and calculations. There are several problems with the classical time-invariant eddy viscosity models: (1) It has been found that the presence of ripple-beds leads to an enhanced wave boundary layer thickness [13]. However, the GM, CJ, SG2000, SG2017 and You models do not consider this effect, resulting in the predicted values of the wave boundary layer thickness being significantly smaller than the estimated values obtained from the laboratory experimental measurements; (2) GM, CJ, SG2000, SG2017 models all assume that eddy viscosities felt by waves and currents within the WBL are the same. However, You et al. [28] derived the expressions of eddy viscosities felt by waves and currents, which were qualitatively analyzed and concluded that the magnitude and vertical distribution of the eddy viscosity felt by waves and currents should not be the same; (3) GM, CJ, SG2000 and SG2017 models neglect the effects of the radiation stress and the wave Reynolds stress. Therefore, in order to modify the shortcomings of the above 1DV models, new 1DV models need to be researched and developed.

In this study, considering the problems of the above classical models, a semi-empirical 1DV model is presented to calculate the mean current profile over the rippled beds in the presence of non-breaking waves while considering the wave-induced shear stress term. The wave boundary layer thickness, physical bed roughness, and apparent bed roughness for the proposed model are discussed. The present model and available measurement data were found to be in good agreement. Moreover, the present model was found to be more accurate than the SG2017 model. Finally, the influencing factors of the mean current profile over the rippled beds in the presence of non-breaking waves were studied by analyzing the data from the laboratory experimental measurements. 


\section{Materials and Methods}

\subsection{Governing Equations}

Neglecting the effects of Coriolis force and kinematic viscosity (the kinematic viscosity of water is relatively small), and assuming the fluid is homogeneous in the horizontal direction and incompressible, the Navier-Stokes equations for the horizontal and vertical velocities are as follows:

$$
\begin{gathered}
\frac{\partial u}{\partial t}+u \frac{\partial u}{\partial x}+w \frac{\partial u}{\partial z}=-\frac{1}{\rho} \frac{\partial P}{\partial x} \\
\frac{\partial w}{\partial t}+u \frac{\partial w}{\partial x}+w \frac{\partial w}{\partial z}=-\frac{1}{\rho} \frac{\partial P}{\partial z}-g
\end{gathered}
$$

The continuity equation reads:

$$
\frac{\partial u}{\partial x}+\frac{\partial w}{\partial z}=0
$$

where $u$ and $w$ both are the instantaneous velocities in the horizontal and vertical directions, respectively; $P$ is the pressure; $\rho$ is the fluid density; and $g$ is the gravity constant.

Using the continuity equation, the momentum equations can be derived from the Navier-Stokes equations:

$$
\begin{gathered}
\frac{\partial u}{\partial t}+\frac{\partial u^{2}}{\partial x}+\frac{\partial u w}{\partial z}=-\frac{1}{\rho} \frac{\partial P}{\partial x} \\
\frac{\partial w}{\partial t}+\frac{\partial w u}{\partial x}+\frac{\partial w^{2}}{\partial z}=-\frac{1}{\rho} \frac{\partial P}{\partial z}-g
\end{gathered}
$$

Suppose $(x, z)$ is a right-angle coordinate system located at the bottom, the $x$-axis is the direction of wave propagation and the $z$-axis is vertically upward. The velocities $u(x, z, t)$, $w(x, z, t)$, and pressure $P(x, z, t)$ are divided into three parts, namely the steady, periodic, and turbulent components, respectively:

$$
\begin{aligned}
u(x, z, t) & =\bar{u}(x, z)+\widetilde{u}(x, z, t)+u^{\prime}(x, z, t) \\
w(x, z, t) & =\bar{w}(x, z)+\widetilde{w}(x, z, t)+w^{\prime}(x, z, t) \\
P(x, z, t) & =\bar{P}(x, z)+\widetilde{P}(x, z, t)+P^{\prime}(x, z, t)
\end{aligned}
$$

According to [8], the steady, periodic, and turbulent components in Equations (6)-(8) can be defined restively as:

$$
\begin{gathered}
\bar{\xi}(x, z)=\lim _{t \rightarrow \infty} \frac{1}{t} \int_{0}^{t} \xi(x, z, t) \mathrm{d} t \\
\widetilde{\xi}(x, z, t)=\lim _{N \rightarrow \infty} \frac{1}{N} \sum_{\mathrm{i}=1}^{N}\left[\xi_{\mathrm{i}}(x, z, t+\mathrm{i} T)-\bar{\xi}(x, z)\right] \\
\xi^{\prime}(x, z, t)=\xi(x, z, t)-\bar{\xi}(x, z)-\widetilde{\xi}(x, z, t)
\end{gathered}
$$

where $T$ is the wave period, $t$ is the time, $N$ is the number of waves, and $\xi$ can be substituted with $u, w$, and $P$. According to [8], if any two components of $u, w, P$ are represented by $f$ and $g$, the relationship between $f$ and $g$ is satisfied as follows:

$$
\begin{gathered}
\overline{f^{\prime}}=\overline{\widetilde{f}}=\overline{\bar{f} \widetilde{g}}=\overline{\bar{f} g^{\prime}}=\overline{\widetilde{f} g^{\prime}}=0 \overline{\bar{f}}=\bar{f} \\
\widetilde{\bar{f} \widetilde{g}}=\bar{f} \widetilde{g} \widetilde{\widetilde{f} \widetilde{g}}=\widetilde{f} \widetilde{g}-\widetilde{\widetilde{f} \widetilde{g}} \widetilde{f^{\prime}}=\widetilde{\bar{f}}=\widetilde{\bar{f} g^{\prime}}=\widetilde{\widetilde{f} g^{\prime}}=0 \quad \widetilde{f}=\widetilde{f}
\end{gathered}
$$


The time-averaged momentum equations in the horizontal and vertical directions can be obtained by substituting Equations (6)-(8) into Equations (4) and (5), respectively, and by using Equation (9), that is, the definition of time averaging and Equation (12).

$$
\begin{gathered}
\frac{\partial\left(\overline{\widetilde{u}^{2}}+\overline{u^{\prime 2}}\right)}{\partial x}+\frac{\partial\left(\overline{\widetilde{u} \widetilde{w}}+\overline{u^{\prime} w^{\prime}}\right)}{\partial z}=-\frac{1}{\rho} \frac{\partial \bar{P}}{\partial x} \\
\frac{\partial\left(\overline{\widetilde{u} \widetilde{w}}+\overline{u^{\prime} w^{\prime}}\right)}{\partial x}+\frac{\partial\left(\overline{\widetilde{w}^{2}}+\overline{w^{\prime 2}}\right)}{\partial z}=-\frac{1}{\rho} \frac{\partial \bar{P}}{\partial z}-g
\end{gathered}
$$

where $\partial \bar{u} / \partial x=0, \bar{w}=0$, according to the assumption of homogeneity of the fluid [29]. Assuming that the first term is much smaller than the second term and can be neglected, the time-averaged pressure at an arbitrary level can be derived from Equation (15):

$$
-\frac{1}{\rho} \bar{P}=g(h+\bar{\eta}+z)+\left(\overline{\widetilde{w}^{2}}+\overline{w^{\prime 2}}\right)
$$

where $\left.\bar{P}\right|_{z=0}=\rho g(h+\bar{\eta})$, according to the hydrostatic approximation. Where $\left.\bar{P}\right|_{z=0}$ is the time-averaged pressure at the bed, $h$ is the local mean depth, $\bar{\eta}$ is the mean surface elevation. Substituting Equation (16) into Equation (14), the following Equation (17) can be obtained:

$$
-\frac{\partial\left(\bar{\tau}_{x z}\right)}{\partial z}=\frac{\partial\left[\left(\overline{\widetilde{u}^{2}}-\overline{\widetilde{w}^{2}}\right)+\left(\overline{{u^{\prime}}^{2}}-\overline{w^{\prime 2}}\right)\right]}{\partial x}+g \frac{\partial \bar{\eta}}{\partial x}
$$

where the total shear force per unit cross-sectional area $\bar{\tau}_{x z}$ is defined as:

$$
\bar{\tau}_{x z}=-\rho\left(\overline{\widetilde{u} \widetilde{w}}+\overline{u^{\prime} w^{\prime}}\right)
$$

Based on the lab measurements from [30], $\left(\overline{u^{\prime 2}}-\overline{w^{\prime 2}}\right)$ is typically much smaller than $\left(\overline{\widetilde{u}^{2}}-\overline{\widetilde{w}^{2}}\right)$ and can be neglected in Equation (17). Thus, Equation (19) can be derived from Equation (17) as:

$$
-\overline{u^{\prime} w^{\prime}}=g \frac{\partial \bar{\eta}}{\partial x} z+\frac{1}{\rho} \bar{\tau}_{0}+\int_{0}^{z} \frac{\partial\left(\overline{\widetilde{u}^{2}}-\overline{\widetilde{w}^{2}}\right)}{\partial x} \mathrm{~d} z+\overline{\widetilde{u} \widetilde{w}}
$$

where $\bar{\tau}_{0}=\left.\bar{\tau}_{x z}\right|_{z=0}$ represents the mean bed shear stress. The effects of wind and the second-order terms caused by the radiation stress in the direction of wave propagation are ignored. $\bar{\tau}_{0}$ can be determined from Equation (20) on the basis of [31]:

$$
\bar{\tau}_{0}=-\rho g h \frac{\partial \bar{\eta}}{\partial x}
$$

In addition, $\bar{\tau}_{0}$ can be expressed in terms of $u_{*_{\mathrm{c}}}$ [29], where $u_{*_{\mathrm{c}}}$ represents the current shear velocity.

$$
\bar{\tau}_{0}=\rho u^{2} *_{c}
$$

The last two terms in Equation (19) are the wave-induced second-order stress terms. Based on the linear wave theory,

$$
\begin{gathered}
\widetilde{u}=\frac{\pi H}{T} \frac{\cosh (k z)}{\sinh (k h)} \cos (k x-\omega t) \widetilde{w}=\frac{\pi H}{T} \frac{\sinh (k z)}{\sinh (k h)} \sin (k x-\omega t) \\
\int_{0}^{z} \frac{\partial\left(\overline{\widetilde{u}^{2}}-\overline{\widetilde{w}^{2}}\right)}{\partial x} \mathrm{~d} z=\int_{0}^{z} \frac{\partial H}{\partial x} \frac{H \omega^{2}}{4 \sinh ^{2}(k h)} \mathrm{d} z=-S_{1} z
\end{gathered}
$$


where $H$ is the wave height, $T$ is the wave period, $k$ is the wave number, and $\omega$ is the radian frequency. $S_{1}$ is a constant that is always positive. Term $\widetilde{\widetilde{u} \widetilde{w}}$ in Equation (19) is the wave Reynolds stress. Several studies have focused on investigating the vertical distribution of the wave Reynolds stress by numerical simulation and lab measurements [29,32-34]. By analyzing the lab measurements, [29] found that the vertical distribution of $\overline{\widetilde{u} \widetilde{w}}$ is approximately linear, and $\widetilde{\widetilde{u} \widetilde{w}}$ can be represented by

$$
\overline{\widetilde{u} \widetilde{w}}=-S_{2} z
$$

In which, $S_{2}$ is a constant that is always positive. Therefore, the wave-induced stress in Equation (19) can be rewritten as

$$
\int_{0}^{z} \frac{\partial\left(\overline{\widetilde{u}^{2}}-\overline{\widetilde{w}^{2}}\right)}{\partial x} \mathrm{~d} z+\overline{\widetilde{u} \widetilde{w}}=-S z
$$

where $S=S_{1}+S_{2},-S z$ represents the wave-induced second-order stress.

Substituting Equations (20), (21), (25) to Equation (19), becomes

$$
-\overline{u^{\prime} w^{\prime}}=u_{*_{\mathrm{c}}}\left|u_{*_{\mathrm{c}}}\right|(1-z / h)-S z
$$

Turbulent Reynolds stresses are expressed as the product of an isotropic current eddy viscosity [8]:

$$
-\overline{u^{\prime} w^{\prime}}=K_{c} \frac{\partial \bar{u}}{\partial z}
$$

where $K_{c}$ is the current eddy viscosity. By substituting Equation (26) into Equation (27), Equation (27) can be rewritten as

$$
\frac{\partial \bar{u}}{\partial z}=\frac{1}{K_{c}}\left[u^{2} *_{c}(1-z / h)-S z\right]
$$

\subsection{Bed Form and the Bed Roughness}

The momentum transfer of fluid and associated sediment dynamics in the near-bed layer are dominated by periodic vortex structures over ripple beds; above this layer, the periodic vortex structures collapse and are replaced by random turbulence [35,36]. It has been suggested by [35] that the height of the vortex layer is approximately twice the ripple height. It was pointed out in $[8,37]$ that the vertical structure of wave velocity is similar to laminar flow in considerably rough flows, such as over a ripple bed. Therefore, the wave eddy viscosity over the rippled-beds can be set to a constant value. The flow in the combined wave-current motion over ripple beds is shown in Figure 1. The physical bed roughness $k_{s}$ and apparent bed roughness $k_{a}$ in the presence of ripples are discussed in Section 3.2. Ripples wash out in strong flows. [38] showed that a significant concentrated near-bed sediment layer develops over rippled-beds in strong flows and increases the value of $k_{s}$. However, this effect is negligible in moderate flows and was not considered in the present model. 


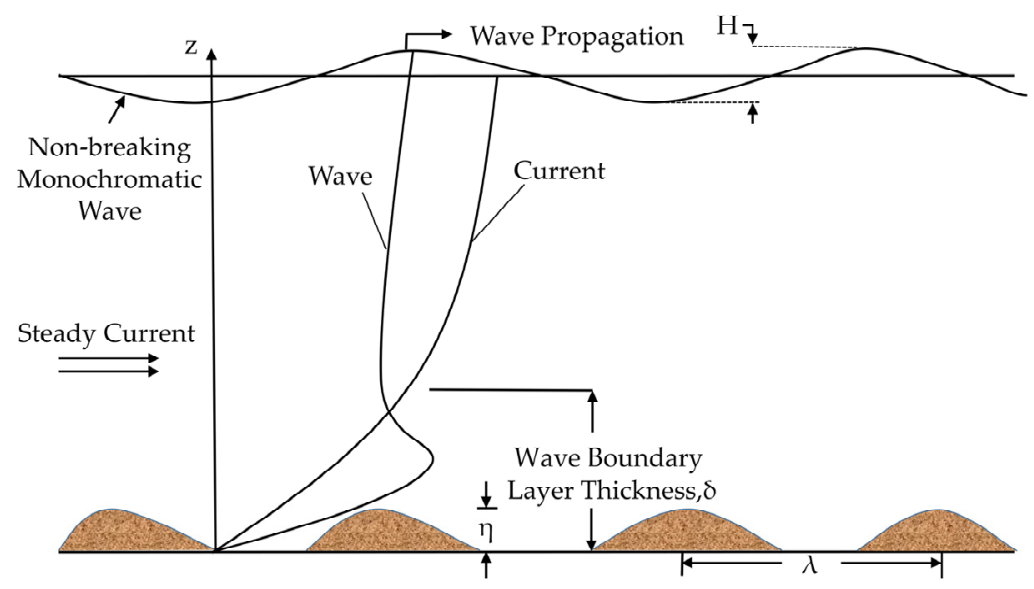

Figure 1. Physical conceptual diagram of flow in combined wave-current motion over ripples (after [39]).

\subsection{Eddy Viscosities}

Assuming current eddy viscosity and wave eddy viscosity are different. Based on the pseudo-laminar eddy viscosity model introduced in [39], the wave eddy viscosity $K_{w}$ can be represented as

$$
K_{w}=180 \frac{\eta^{4}}{\lambda^{2} T}
$$

To determine the current velocity distribution within and outside the wave boundary layer, there are three type of current eddy viscosities:

$$
\begin{gathered}
K_{c}=\kappa u_{* c} z\left(1-\frac{z}{h}\right) z>\delta_{1} \\
K_{c}=\frac{1}{m} \kappa u_{* c w} \delta_{1} \delta<z \leq \delta_{1} \\
K_{c}=\frac{1}{m} \kappa u_{* c w} z z \leq \delta
\end{gathered}
$$

where $u_{* \mathrm{c} w}$ is the characteristic shear velocity within the wave boundary layer and reflects the combination of the maximum shear stress for the wave and current [14]. In order to make the current velocity profile continuous, a scaling parameter $\mathrm{m}$ was added. $\delta$ is the thickness of the wave boundary layer and the value of $\delta$ will be discussed in Section 3.1. $\delta_{1}$ represents the height of the transition layer. According to [17], the relationship between $\delta_{1}$ and $\delta$ is as follows:

$$
\frac{\delta}{\delta_{1}}=1+\beta \frac{k_{b}}{A_{b}}
$$

where, $k_{b}$ is the bed roughness in the presence of waves over ripple beds, which equals to $6.4 \eta . A_{b}$ is the semi-excursion amplitude. $\beta=0.3$ is an empirical coefficient. The distributions of the wave and current eddy viscosities are shown in Figure 2. 


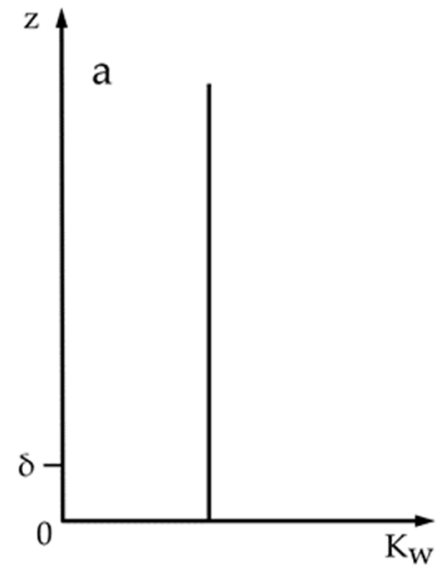

(a)

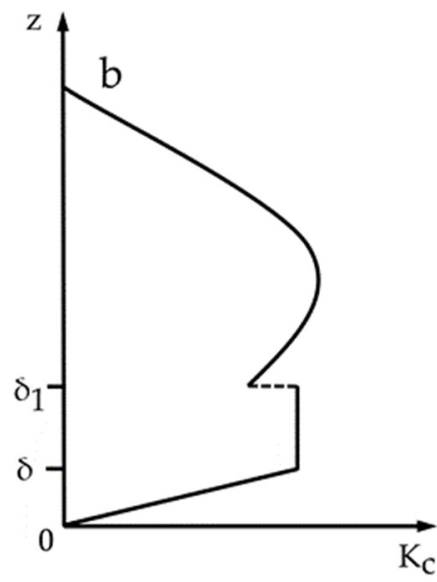

(b)

Figure 2. The distributions of the eddy viscosities (a) Wave eddy viscosity; (b) Current eddy viscosity.

2.4. Solutions of $\bar{u}(z)$ and $\widetilde{u}(z)$

\subsubsection{Solution of $\bar{u}(z)$}

By combining Equations (28) and (30) and using boundary conditions, the current velocity distribution outside the transition layer can be obtained:

$$
\bar{u}=\frac{u_{*_{\mathrm{c}}}}{\kappa} \ln \frac{z}{z_{0 a}}+\int_{z_{0 a}}^{z} \frac{-S z}{\kappa u_{\mathrm{c}} z(1-z / h)} \mathrm{d} z
$$

where $z_{0 a}=k_{a} / 30$. Assuming $z_{0 a} \ll h$, Equation (34) can be rewritten as:

$$
\bar{u}=\frac{u_{*_{c}}}{\kappa} \ln \frac{z}{z_{0 a}}+\frac{S h}{\kappa u_{* c}} \ln (1-z / h) z>\delta_{1}
$$

The current velocity distribution within the transition layer and the wave boundary layer can be obtained by combining Equations (28) and (31), (32) and using boundary conditions:

$$
\begin{gathered}
\bar{u}=m\left[\frac{u_{* \mathrm{c}}^{2}}{\kappa u_{* \mathrm{c} w}} \ln \left(\frac{z}{z_{0}}\right)-\frac{\frac{u^{2} * \mathrm{c}}{h}+S}{\kappa u_{* \mathrm{c} w}}\left(z-z_{0}\right)\right] \quad z_{0} \leq z \leq \delta \\
\bar{u}=m\left[\frac{u_{* \mathrm{c}}^{2}}{\kappa u_{* \mathrm{c} w} \delta}(z-\delta)-\frac{\frac{u^{2} * \mathrm{c}}{h}+S}{2 \kappa u_{* \mathrm{c} w} \delta}\left(z^{2}-\delta^{2}\right)\right]+\bar{u}(\delta) \quad \delta \leq z \leq \delta_{1}
\end{gathered}
$$

where $z_{0}=k_{s} / 30$, and $\kappa=0.4$ is the Von Kármán number. The formulae for $z_{0}$ and $z_{0 a}$ are presented in Section 3.2.

By adopting the top-to-bottom calculation sequence, the current distribution above the transition layer can first be calculated using Equation (35). The value of the scaling parameter, $\mathrm{m}$, can be calculated by substituting $z=\delta_{1}$ into Equations (35) and (37) respectively, and making $\bar{u}$ calculated by Equations (35) and (37) equal. Further, the current velocity distribution within the transition layer and the wave boundary layer can be calculated using Equations (36) and (37).

Based on [29], the value of $S$ in Equation (35) can be established by a reference current velocity $\bar{u}_{r}$ and a reference height $z_{r}$ where $\bar{u}_{r}$ is located:

$$
S=\frac{\kappa u_{* \mathrm{c}}\left(\bar{u}_{r}-\frac{u_{*_{c}}}{\kappa} \ln \frac{z_{r}}{z_{0 a}}\right)}{h \ln \left(1-z_{r} / h\right)}
$$




\subsubsection{Solution of $\widetilde{u}(z)$}

The solution of $\widetilde{u}(z)$ is analogous to the solution of velocity in the laminar boundary layer:

$$
\widetilde{u}=\left(1-\mathrm{e}^{-(1+\mathrm{i}) z / \delta^{\prime}}\right) u_{b} \mathrm{e}^{\mathrm{i} \omega t}
$$

where $u_{b}$ is the free-stream wave orbital velocity, $\delta^{\prime}=\sqrt{2 K_{w} / \omega}, K_{w}$ can be calculated using Equation (29).

\subsection{Shear Velocities and Wave Friction Factor}

See equation below:

$$
\tau_{w m}=u_{* w m}^{2}=\frac{1}{2} f_{w} C_{R} \rho u_{b}^{2}
$$

where $f_{w}$ is the wave friction factor, $C_{R}$ is a parameter that indicates the enhancement of the currents by waves. The relationship between $u_{* c w}$ and wave shear velocity $u_{* w m}$ can be established by $C_{R}$ :

$$
u_{* c w}^{2}=C_{R} u_{* w m}^{2}
$$

where $C_{R}$ can be expressed as

$$
C_{R}=\left[1+2\left(\frac{u_{* \mathrm{c}}}{u_{* w m}}\right)^{2} \cos \varphi_{c w}+\left(\frac{u_{* \mathrm{c}}}{u_{* w m}}\right)^{4}\right]^{\frac{1}{2}}
$$

where $\varphi_{c w}\left(0^{\circ} \leq \varphi_{c w} \leq 90^{\circ}\right)$ is the angle between the mean current and wave.

The maximum shear stress for wave $\tau_{w m}$ can also be expressed as

$$
\frac{\tau_{w m}}{\rho}=u_{* w m}^{2}=K_{w} \frac{\partial \widetilde{u}}{\partial z}=K_{w} \frac{u_{b}}{\eta} \Gamma_{w s}
$$

where $\Gamma_{w s}$ is the dimensionless wave shear. On the basis of Equation (39), $\Gamma_{w s}$ can be represented as

$$
\Gamma_{w s}=\frac{\eta}{u_{b}} \frac{\partial \widetilde{u}}{\partial z}=\eta\left|\mathrm{e}^{-(1+\mathrm{i}) z / \delta^{\prime}} \cdot \frac{1+\mathrm{i}}{\delta^{\prime}} \mathrm{e}^{\mathrm{i} \omega t}\right|
$$

The expression of wave friction factor $f_{w}$ can be obtained by combining Equations (40), (43) and (44):

$$
f_{w}=\frac{K_{w}}{\eta} \tau_{w s} \frac{C_{R}}{u_{b}}
$$

\subsection{Solution Procedure}

To calculate the mean current profile, the input parameters of the present model used are as follows: $\lambda, \eta, u_{b}, a_{b}, u_{c}, \bar{u}_{r}, z_{r}$, and a set of estimates for $u_{* c}$ and $u_{* c w}$. The solution procedure was similar to that in [16].

1. The initial $C_{R}$ was equal to 1 . The value of $u_{* w m}$ can be calculated by Equation (40), then a new value of $C_{R}$ can be obtained by substituting $u_{* \mathrm{c}}$ and $u_{* v w}$ into Equation (42).

The value of $u_{* c w}$ can be derived by substituting $C_{R}$ and $u_{* w m}$ into Equation (41).

2. Repeat step (1) until $u_{* c w}$ converges. This is the inner loop.

3. Calculate the mean current profile using Equations (35)-(37). If the calculated value of $\bar{u}\left(z_{r}\right) \neq \bar{u}_{r}$, then the process from step (1) is repeated with a new $u_{* \mathrm{c}}$ until the calculated $\bar{u}\left(z_{r}\right)$ is equal to $\bar{u}_{r}$. This is the outer loop.

The value of $u_{* \mathrm{c}}$ can be corrected iteratively by the secant method, and the value of $S$ can be derived by substituting the estimate of $u_{* c}, \bar{u}_{r}, z_{r}$ into Equation (38). Figure 3 shows the diagram of the solution procedure. 


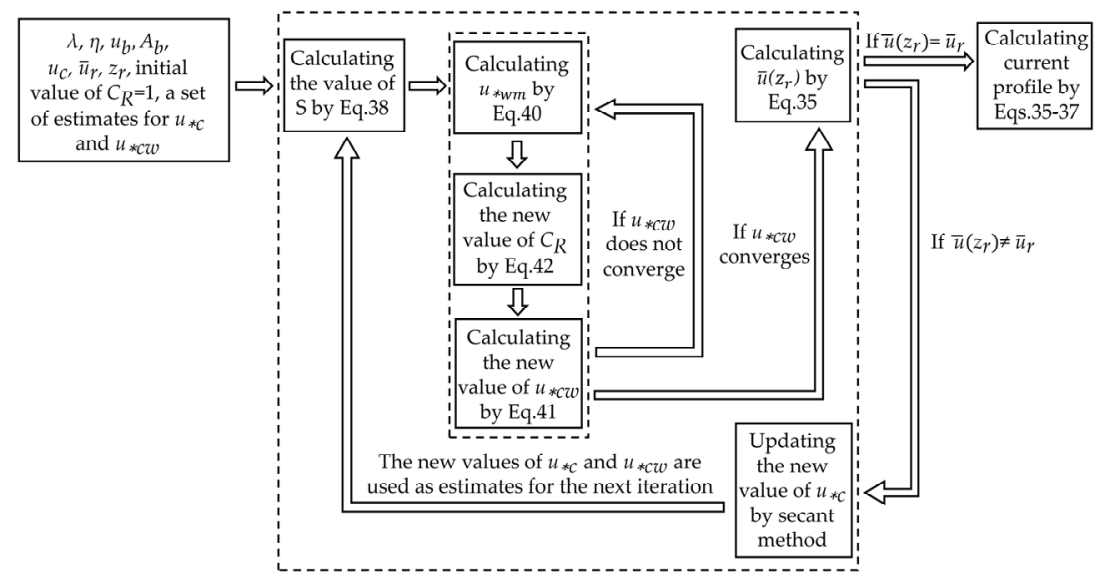

Figure 3. Diagram of the solution procedure.

\section{Predictions of Boundary Layer Thickness and Bed Roughness}

\subsection{Thickness of the Wave Boundary Layer}

The thickness of the wave boundary layer is one of the most significant characteristics that a model to be predicted. The classical GM, CJ, SG2000, SG2017, and You models fail to accurately predict this parameter when disposing of large roughness elements, such as ripples and dunes. Regarding the wave boundary layer thickness $\delta$, Sleath [40] proposed a classical definition, where $\delta$ is the distance between the mean bed level and the level at which the velocity defect should be $5 \%$ of the free-stream wave orbital velocity $u_{b}$. In the lab experiments by [40], the rough beds were composed of a single layer of sand and gravel on a flat bed, which differs from the ripple beds. Hence it is questionable whether the definition of [40] can accurately predict the thickness of the wave boundary layer in the present model. Based on the findings by [39], the proportion of velocity defects to $u_{b}$ is denoted by $A$ and $\delta$ can be expressed as:

$$
\delta=B \sqrt{2 K_{w} / \omega}
$$

where $B$ is the factor to be determined. The relationship between $A$ and $B$ can be obtained by combining Equations (39) and (46), where the imaginary parts in Equation (46) are ignored.

$$
\mathrm{e}^{-B}=A
$$

To study the characteristics of fluid motion and bed roughness in combined wavecurrent flows over ripples, laboratory experiments have been conducted by several studies $[10,41-43]$. The experiments conditions and estimates of the wave boundary layer thickness obtained visually from the experimental velocity amplitude profiles are shown in Table 1 , where $A=1 \%, 2 \%, 3 \%, 4 \%, 5 \%$ and the values of the corresponding $B$ can be obtained by Equation (47). As shown in Figure 4, Equation (46) best fits the data when $A=2 \%$, that is, $B=3.91$. Hence, the wave boundary layer thickness in combined wave-current flows over ripple beds can be accurately predicted using Equation (46) with $B=3.91$. The wave boundary layer thickness $\delta$ is shown in Figure 5 . 
Table 1. Experiments conditions and estimates of $\delta$.

\begin{tabular}{cccc}
\hline Exp. & Experimental $\delta /(\mathbf{c m})$ & $\eta /(\mathbf{c m})$ & $\lambda /(\mathbf{c m})$ \\
\hline $\mathrm{a}^{1}$ & 6.0 & 1.5 & 10 \\
$\mathrm{~b}^{1}$ & 7.2 & 1.5 & 10 \\
$\mathrm{c}^{1}$ & 7.0 & 1.5 & 10 \\
$\mathrm{n}^{1}$ & 3.5 & 1.5 & 20 \\
$165-02^{2}$ & 2.7 & 0.7 & 5 \\
$\mathrm{PWO}^{3}$ & 7.3 & 1.5 & 10 \\
$\mathrm{WC1}^{4}$ & 15.9 & 3.5 & 22 \\
\hline
\end{tabular}

${ }^{1}$ the experiments in [41], ${ }^{2}$ the experiment in [42]. ${ }^{3}$ the experiment in [43]. ${ }^{4}$ the experiment in [10].

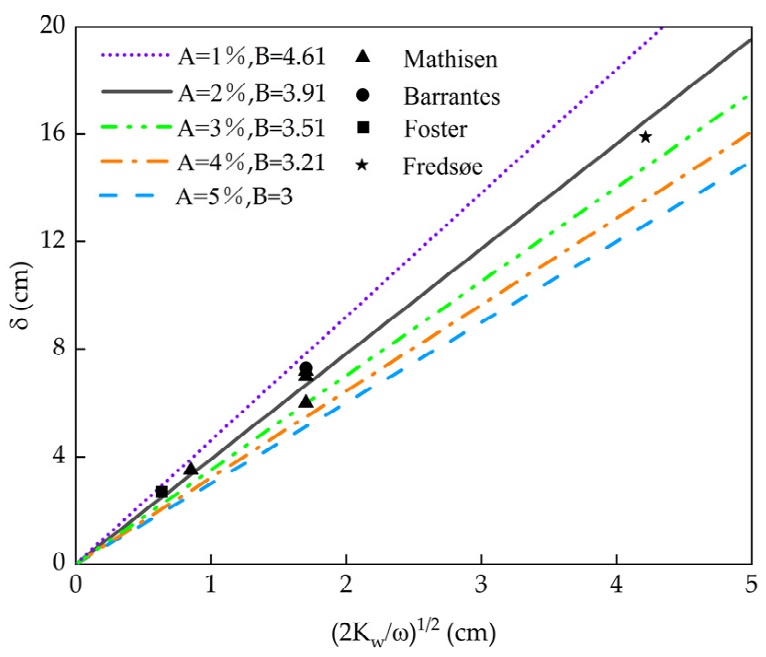

Figure 4. $\delta$ as a function of $\sqrt{2 K_{w} / \omega}$.

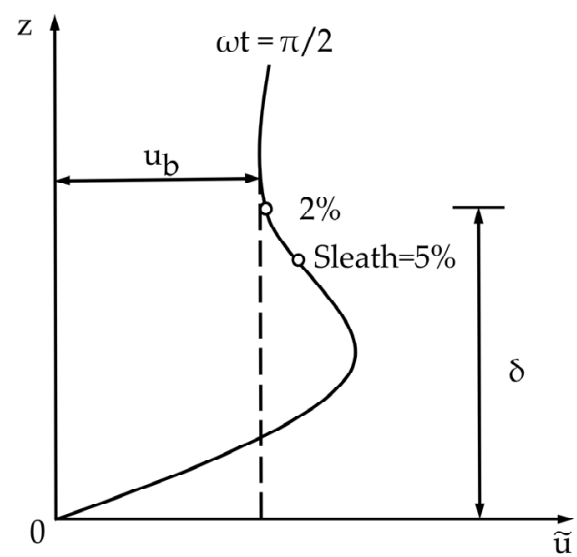

Figure 5. Wave boundary layer thickness $\delta$.

\subsection{Physical Bed Roughness and Apparent Bed Roughness}

To study the physical bed roughness and apparent bed roughness with ripples, several researchers have performed laboratory sink experiments [10,12,13,44-47]. The experiments conditions are listed in Table 2. Many researchers have derived empirical formulae for $k_{s}[8,10,48]$. However, they did not consider the ripple steepness as the dividing line, hence, different empirical formulae can be used to express the physical bed roughness for small and large ripple steepness. As shown in Figure 6a, the ripple steepness of the data above the dot-and-dash line is greater than 0.13 and less than 0.13 for data below the dot-and-dash line, data with $\eta / \lambda>0.13$ and $\eta / \lambda \leq 0.13$ can be summarized as two different empirical 
formulae. The findings of [12], which indicates a large ripple steepness $=0.28>0.13$, but a small $k_{s},-$ is an exception. This is due to its particularly small value of $\eta$.

$$
\begin{gathered}
k_{s}=34.24 \eta^{2} / \lambda \eta / \lambda>0.13 \text { and } \eta>0.8 \mathrm{~cm} \\
k_{s}=10.85 \eta^{2} / \lambda \eta / \lambda \ll 0.13
\end{gathered}
$$

Table 2. Experiments conditions. The legends in the table are applicable to Figure 6a-d.

\begin{tabular}{cccccccc}
\hline Author & Legend & $\boldsymbol{\varphi}_{\boldsymbol{c w}}$ & $\boldsymbol{H} / \boldsymbol{h}$ & $\boldsymbol{a}_{\boldsymbol{b}} / \boldsymbol{k}_{\boldsymbol{s}}$ & $\boldsymbol{h} / \boldsymbol{k}_{\boldsymbol{s}}$ & $\boldsymbol{\eta} / \boldsymbol{\lambda}$ & $\eta /(\mathrm{cm})$ \\
\hline Kemp [12] & $\times$ & $0^{\circ}$ & $0.11-0.23$ & $0.5-0.9$ & 10 & 0.28 & 0.50 \\
Havinga [46] & $\bullet$ & $60^{\circ}, 90^{\circ}$ & $0.16-0.33$ & $4.6-94.9$ & $17.5-506$ & $0.07-0.13$ & $0.6-1.3$ \\
Nieuwjaar [44] & & $0^{\circ}$ & $0.15-0.30$ & $0.7-2.3$ & $3.7-10.3$ & $0.10-0.18$ & $1.5-1.9$ \\
Mathisen [47] & $\triangleright$ & $0^{\circ}$ & $0.19-0.29$ & $0.2-0.4$ & 3.0 & 0.15 & 1.50 \\
Mathisen [47] & & $0^{\circ}$ & 0.26 & $0.3-0.6$ & $2.5-5$ & 0.075 & 1.50 \\
Fredsøe [10] & $\square$ & $0^{\circ}$ & 0.313 & 1.2 & 4.9 & 0.16 & 3.50 \\
Van Kampen & $\star$ & $0^{\circ}$ & $0.15-0.30$ & $0.5-2.8$ & $4.2-12.4$ & $0.13-0.15$ & $0.8-1.5$ \\
[45] & $\star$ & & & & & & \\
\hline
\end{tabular}
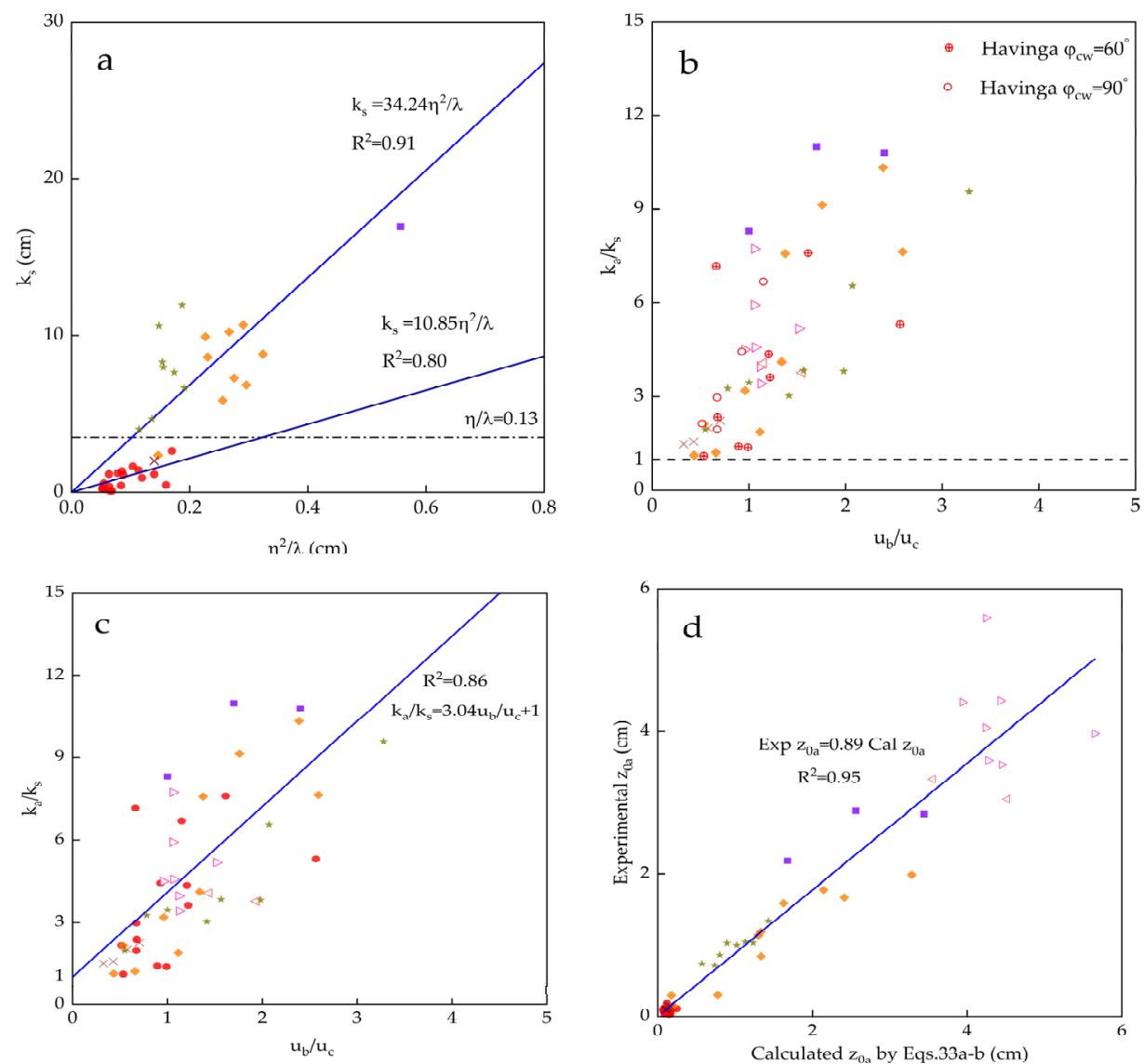

Figure 6. Experimental $k_{s}, k_{a}$ and linear regression. (a) $k_{s}$ as a function of $\eta^{2} / \lambda$; (b) experimental $k_{a} / k_{s}$, where the data in Havinga [46] are divided into those with $\varphi_{c w}=60^{\circ}$ and those with $\varphi_{c w}=90^{\circ}$; (c) $k_{a} / k_{s}$ as a function of $u_{b} / u_{c}$; (d) linear regression between experimental $z_{0 a}$ and calculated $z_{0 a}$.

The values of apparent bed roughness $k_{a}$ were determined from the mean current profiles measured in the laboratory experiments are shown in Figure $6 b$, and the following conclusions can be drawn from Figure $6 \mathrm{~b}$. 
1. There is a distinct trend where $k_{a} / k_{s}$ increase with $u_{b} / u_{c}$, where $u_{c}$ is the depthaveraged current velocity. When $u_{b} / u_{c}$ is positive, $u_{b} / u_{c}>1$. These conclusions are similar to those summarized in [10].

2. For a given $u_{b} / u_{c}, k_{a} / k_{s}$ increase with $H / h$, that is, the higher the waves, the larger the apparent bed roughness.

3. For a given $u_{b} / u_{c}, \varphi_{c w}$ is supposed to be a potential impact factor for $k_{a} / k_{s}$. Unfortunately, no exact effect of $\varphi_{c w}$ on $u_{b} / u_{c}$ can be identified. In addition, when $u_{b} / u_{c}>1$, $k_{a} / k_{s}$ will be smaller with increasing $\varphi_{c w}$. This may be because $\varphi_{c w}$ has little effect on $k_{a} / k_{s}$.

Ignoring the effect of $\varphi_{c w}, k_{a} / k_{s}$ can be expressed as a function of $u_{b} / u_{c}$, as shown in Figure 6c.

$$
\frac{k_{a}}{k_{s}}=3.04 \frac{u_{b}}{u_{c}}+1
$$

By substituting Equations (48) and (49) to Equation (50), $z_{0 a}=k_{a} / 30$ can be expressed as

$$
\begin{gathered}
z_{0 a}=1.14 \frac{\eta^{2}}{\lambda}\left(3.04 \frac{u_{b}}{u_{c}}+1\right) \eta / \lambda>0.13 \text { and } \eta>0.8 \mathrm{~cm} \\
z_{0 a}=0.36 \frac{\eta^{2}}{\lambda}\left(3.04 \frac{u_{b}}{u_{c}}+1\right) \eta / \lambda \ll 0.13
\end{gathered}
$$

$[9,49]$ derived classical empirical formulae for the apparent bed roughness. These two empirical formulae and Equations (51) and (52) were selected, and the mean absolute error $(M A E)$, the mean absolute percentage error (MAPE), root-mean-square error (RMSE), and index of agreement $(d)$ were used to compare the calculated results with the experimental $z_{0 a}$. Based on [50], the MAE, MAPE, RMSE, and $d$ can be represented as

$$
\begin{gathered}
M A E=\sum_{i=1}^{N}\left|\left(x_{i}^{c}-x_{i}^{m}\right)\right| / N \\
M A P E=\sum_{i=1}^{N}\left|\left(x_{i}^{c}-x_{i}^{m}\right) / x_{i}^{m}\right| \cdot 100 \% / N \\
R M S E=\sqrt{\sum_{i=1}^{N}\left(x_{i}^{c}-x_{i}^{m}\right)^{2} / N} \\
d=1-\sum_{i=1}^{N}\left(x_{i}^{c}-x_{i}^{m}\right)^{2} / \sum_{i=1}^{N}\left(\left|x_{i}^{c}-\bar{x}\right|+\left|x_{i}^{m}-\bar{x}\right|\right)^{2}
\end{gathered}
$$

where $x_{i}^{c}$ represents the calculated values, $x_{i}^{m}$ represents the values estimated from the mean current profiles measured in laboratory experiments, $\bar{x}$ represents the average of $x_{i}^{m}$, and $N$ represents the total number of data and there are 48 sets of data. The calculated results are presented in Table 3. From the established data sample and the index of agreement $d$, the values of $M A E, R M S E$ of result calculated from Equations (51) and (52) are all the smallest, those obtained from the formula proposed by Van Rijn [9] are the second largest, those obtained from the formula proposed by Sleath [49] are the largest, and the value of $d$ of result calculated from Equations (51) and (52) are all the largest. Hence, Equations (51) and (52) has have improved the accuracy of the prediction of $k_{a}$ compared with the existing formulae. The linear regression between experimental $z_{0 a}$ and calculated $z_{0 a}$ is shown in Figure 6d. 
Table 3. Comparison between calculated and experimental $z_{0 a}$ of different formulae.

\begin{tabular}{ccccc}
\hline Author & Formula & MAE & RMSE & $d$ \\
\hline Sleath & $z_{0 a}=z_{0}\left(1+0.19\left(u_{b} / u_{*_{c}}\right)\left(A_{b} / k_{s}\right)^{0.5}\right)$ & 0.738 & 1.15 & 0.750 \\
Van Rijn & $z_{0 a}=z_{0} \exp \left(\gamma u_{b} / u_{c}\right)$ & 0.638 & 0.893 & 0.906 \\
& Equations $(51)$ and $(52)$ & 0.345 & 0.626 & 0.961 \\
\hline
\end{tabular}

\section{Results}

In order to examine the accuracy of the present model, the calculated results of the present model and the SG2017 model [17] were compared with the laboratory measurements of Havinga [46] and van der Kaaij and Nieuwjaar [44], as shown in Figure 7. It can be demonstrated that the present model is in good agreement with laboratory measurements. The mean absolute percentage error (MAPE), the mean absolute error (MAE), root-meansquare error (RMSE), and index of agreement $(d)$ were used to compare the present model and the SG2017 model with the laboratory measurements, as shown in Table 4. As seen in Table 4, the accuracy of the present model is significantly better than that of the SG2017 model. Although the accuracy of the present model is slightly less than that of the SG2017 model in cases T14 30-90, T7.5 40-0, and T12 10-0, the shape and trend of the current profiles calculated by the present model are in better agreement with the laboratory measurements.
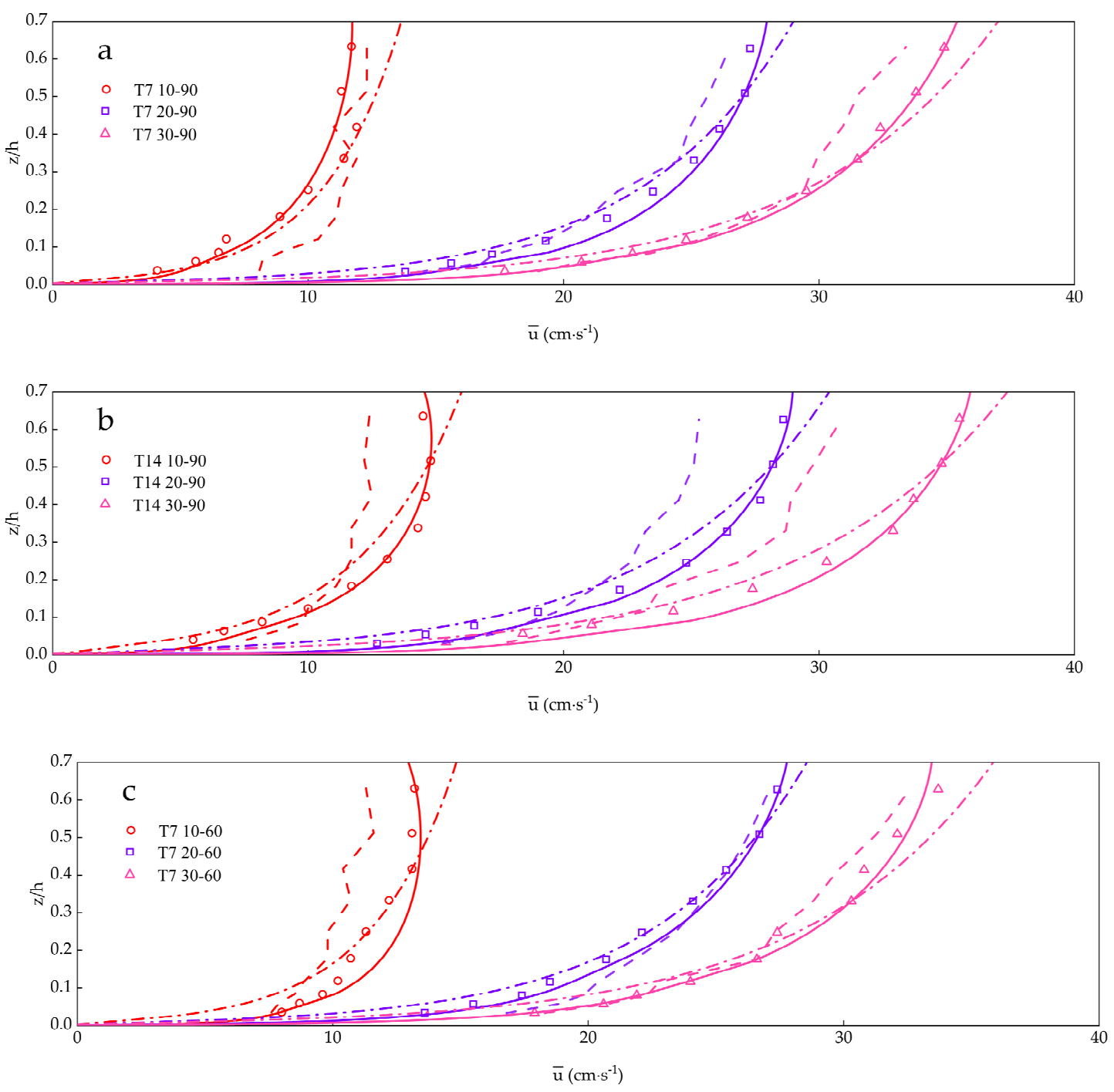

Figure 7. Cont. 

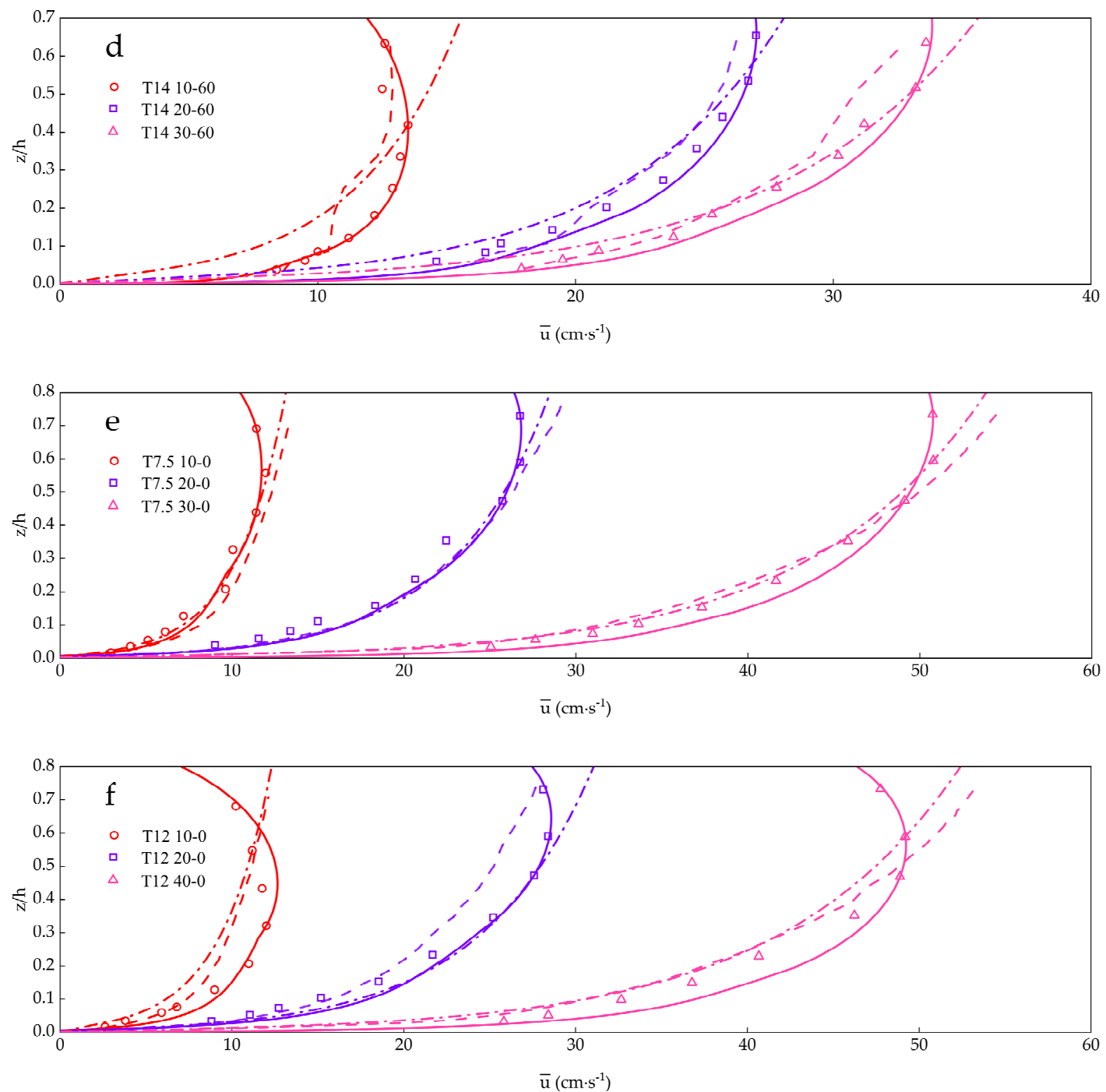

Figure 7. Comparison of the present model, the SG2017 model, and the laboratory measurements. For example, T7 10-90 represents a laboratory experiment with a wave height of approximately $7 \mathrm{~cm}$, a current velocity of approximately $10 \mathrm{~cm} / \mathrm{s}$ and $\varphi_{c w}=90^{\circ}$. Scatters are the laboratory measurements in combined wave-current flows, the straight lines represent the calculated results of the present model, the dot-and-dash lines represent the calculated results of the SG2017 model, and the dashed lines are the lab measurement in pure currents. (a-d) Comparison of the present model with Havinga [46]; $(\mathbf{e}, \mathbf{f})$ comparison of the present model with van der Kaaij and Nieuwjaar [44]. 
Table 4. Comparison of accuracy of the present model and the SG2017 model in calculating current velocity.

\begin{tabular}{ccccccccc}
\hline \multicolumn{3}{c}{ The Present Model } & \multicolumn{4}{c}{ SG2017 } \\
\hline EXP. & MAPE & MAE & RMSE & $\boldsymbol{d}$ & MAPE & MAE & RMSE & $\boldsymbol{d}$ \\
\hline T7 10-90 & $6.44 \%$ & 0.444 & 0.589 & 0.986 & $10.44 \%$ & 0.815 & 0.966 & 0.969 \\
T7 20-90 & $4.25 \%$ & 0.768 & 0.952 & 0.989 & $6.32 \%$ & 1.091 & 1.481 & 0.980 \\
T7 30-90 & $1.30 \%$ & 0.294 & 0.410 & 0.999 & $5.25 \%$ & 1.188 & 1.565 & 0.985 \\
T14 10-90 & $5.10 \%$ & 0.395 & 0.525 & 0.993 & $8.36 \%$ & 0.847 & 0.934 & 0.982 \\
T14 20-90 & $5.09 \%$ & 0.812 & 1.147 & 0.988 & $9.41 \%$ & 1.589 & 2.173 & 0.971 \\
T14 30-90 & $6.50 \%$ & 1.311 & 1.787 & 0.980 & $6.23 \%$ & 1.375 & 1.618 & 0.988 \\
T7 10-60 & $4.79 \%$ & 0.527 & 0.685 & 0.966 & $12.57 \%$ & 1.186 & 1.605 & 0.898 \\
T7 20-60 & $2.52 \%$ & 0.485 & 0.574 & 0.996 & $6.63 \%$ & 1.050 & 1.656 & 0.975 \\
T7 30-60 & $0.96 \%$ & 0.282 & 0.497 & 0.998 & $8.41 \%$ & 1.861 & 2.448 & 0.960 \\
T14 10-60 & $1.49 \%$ & 0.165 & 0.287 & 0.993 & $22.32 \%$ & 2.319 & 2.719 & 0.760 \\
T14 20-60 & $4.50 \%$ & 0.807 & 1.009 & 0.984 & $6.66 \%$ & 1.243 & 1.423 & 0.977 \\
T14 30-60 & $4.26 \%$ & 1.003 & 1.154 & 0.988 & $7.66 \%$ & 1.610 & 2.291 & 0.967 \\
T7.5 10-0 & $6.12 \%$ & 0.390 & 0.495 & 0.993 & $6.43 \%$ & 0.406 & 0.567 & 0.993 \\
T7.5 20-0 & $7.95 \%$ & 1.089 & 1.372 & 0.986 & $9.62 \%$ & 1.407 & 1.808 & 0.977 \\
T7.5 40-0 & $6.04 \%$ & 1.929 & 2.408 & 0.980 & $4.58 \%$ & 1.449 & 1.997 & 0.990 \\
T12 10-0 & $12.87 \%$ & 0.774 & 0.964 & 0.976 & $20.38 \%$ & 1.481 & 1.659 & 0.939 \\
T12 10-0 & $11.06 \%$ & 1.437 & 1.931 & 0.979 & $9.18 \%$ & 1.420 & 1.659 & 0.986 \\
T12 10-0 & $7.08 \%$ & 2.442 & 2.740 & 0.972 & $9.90 \%$ & 3.335 & 3.895 & 0.959 \\
\hline
\end{tabular}

\section{Discussion}

The problem of the classical eddy viscosity models underestimating the wave boundary layer thickness was explained in detail in [47,51]. Madsen and Salles [51] introduced a scaling factor to represent the effect of the presence of ripples on the increase in the wave boundary layer thickness. However, the classical eddy viscosity models GM, CJ, SG2000, SG2017 and You ignored this increasing effect. As shown in Figure 7, the SG2017 model fails to have a good agreement with the laboratory measurements, mainly reflected by the small calculated values of the current velocity in the near-bed layer $(z / h<0.2)$ and the absence of deviations in the near-surface layer $(z / h>0.6)$ of current profiles. The former phenomenon may be due to the inappropriate assumption of the current and wave eddy viscosity within the wave boundary layer, and the latter may be due to the neglect of the wave-induced shear stresses. Moreover, the effect of the presence of waves on the mean current profile can be seen in Figure 7 as follows:

1. In the near-bed layer $(z / h<0.2)$ and near-surface layer $(z / h>0.6)$, the presence of waves leads to a reduction in the current velocities, and an enhancement in the middle layer.

2. The deviation of the current velocity profile caused by the presence of waves is relatively notable when the free stream wave orbital velocity, $u_{b}$, is relatively large with respect to the depth-averaged current velocity $u_{c}$.

3. For a given $u_{b}$ and $u_{c}$, the smaller the $\varphi_{c w}$, the lower is the level at which the current velocities begin to decrease.

The first two findings were similar to those in [9]. Equation (34) qualitatively explains the deviation of the current velocity distribution in the near-surface layer from the logarithmic distribution as a result of the wave-induced second-order shear stress. Physically, the deviation is due to the combination of the wave-induced second-order shear stress $(-S z)$ and the shear stress induced by bottom friction. The magnitude of the shear stress induced by bottom friction reaches its maximum on the bed and gradually decreases from the bed to the surface, and the value of the shear stress induced by the bottom friction is positive. The magnitude of the wave-induced second-order shear stress, $-S z$, increases linearly from the bed upward and $-S z<0$. Therefore, the wave-induced second-order shear stress $-S z$ and the shear stress induced by bottom friction are superimposed to form $a$ " $z$ " type shape. The magnitude of the combined shear stress reaches its maximum at the bed, decreases from the bed upward, and becomes zero at a certain level, then increases 
upwards. That is, the combined shear stress changes from positive to negative from the bed to the surface, and the current velocity decreases upwards above the level at which the combined shear stress becomes zero. This indicates that the level at which the current velocities begin to decrease can reflect the magnitude of $-S z$ relative to the magnitude of the shear stress induced by bottom friction. For a larger $-S z$, the combined shear stress will reduce to zero at a lower level. Denote the level at which the current velocities begin to decrease with $z_{d}$. It is clear from finding 2 that for a given $\varphi_{c w}$, the stronger the waves are relative to the currents, the greater is the influence of $-S z$. Hence, the wave parameters and the intensity of the wave relative to the current are both the influencing factors of $-S z$, as mentioned in [29].

According to [52], the wave height attenuation $\partial H / \partial x$ and the bed slope are both influencing factors of the wave Reynolds stress $\widetilde{\widetilde{u} \widetilde{w}}$ in Equation (25). Moreover, $\partial H / \partial x$ is the primary influencing factor of $\int_{0}^{z} \partial\left(\overline{\widetilde{u}^{2}}-\overline{\widetilde{w}^{2}}\right) / \partial x \mathrm{~d} z$ in Equation (25). Hence $\partial H / \partial x$ is an influencing factor of $-S z$ when the bed slope is ignored. From Equations (40) and (45), it can be found that large $\eta$ and $\eta / \lambda$ potentially lead to large bottom stresses, which results in a large wave height attenuation $\partial H / \partial x$. The laboratory measurements of current velocities in combined wave-current flows and current only in van der Kaaij and Nieuwjaar [44] and Nap and Van Kampen [45] are shown in Figure 8. As shown in Figure 8, for similar wave-current conditions, $z_{d}$ is smaller for a large size of the ripples (the larger size of the ripples means that the ripple height is larger than others when the ripple steepness are approximately the same). Hence, the size of the ripples is also an influencing factor of $-S z$. As can be seen in Figure $8 \mathrm{a}, z_{d}$ in van der Kaaij and Nieuwjaar [44] and those in Nap and Van Kampen [45] are nearly the same, which may be due to the differences in ripple size being too small or the presence of differences in current conditions in the two laboratory experiments.
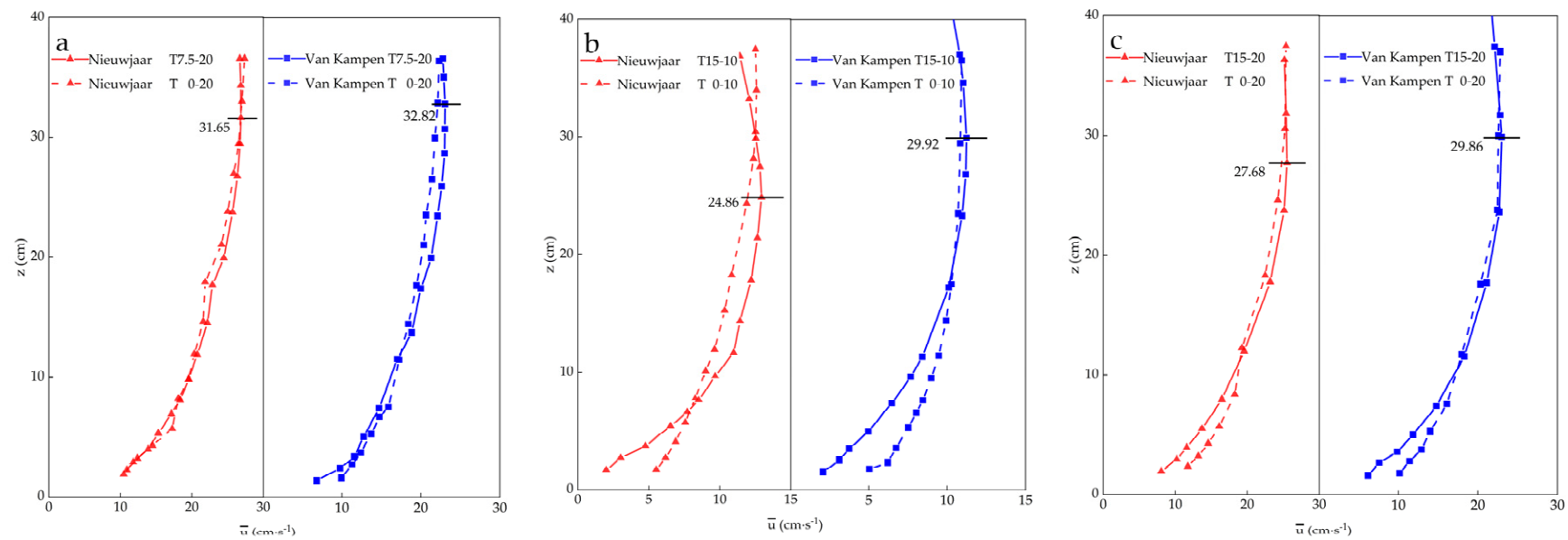

Figure 8. Laboratory measurements of $\bar{u}$ in two similar wave-current conditions in ripples of different sizes. $\varphi_{c w}=0^{\circ}$ in all the experiments. For example, T7.5-20 represents a lab experiment with a wave height of approximately $7.5 \mathrm{~cm}$, a current velocity of approximately $20 \mathrm{~cm} / \mathrm{s}$. The short horizontal lines represent $z_{d}$. (a) $\eta=1.5 \mathrm{~cm}$ and $\lambda=9.9 \mathrm{~cm}$ in van der Kaaij and Nieuwjaar [44], and $\eta=1.27 \mathrm{~cm}$ and $\lambda=8.44 \mathrm{~cm}$ in Van Kampen [45]; (b) $\eta=1.8 \mathrm{~cm}$ and $\lambda=10 \mathrm{~cm}$ in van der Kaaij and Nieuwjaar, and $\eta=0.86 \mathrm{~cm}$ and $\lambda=6.47 \mathrm{~cm}$ in Van Kampen; (c) $\eta=1.6 \mathrm{~cm}$ and $\lambda=11.1 \mathrm{~cm}$ in van der Kaaij and Nieuwjaar, and $\eta=1.1 \mathrm{~cm}$ and $\lambda=7.79 \mathrm{~cm}$ in Van Kampen.

The findings revealed that the $\varphi_{c w}$ may be an influencing factor of $-S z$. By using Equation (38), the values of $S$ estimated from the laboratory experiments of van der Kaaij and Nieuwjaar [44] and Havinga [46] are shown in Figure 9a. As shown in Figure 9a, $S / u^{2}{ }_{b} \mathcal{K}$ is a linear function of $u_{* \mathrm{c}} / u_{b}$ and the values of $S / u^{2}{ }_{b} \mathcal{K}$ are divided into three segments owing to different $\varphi_{c w}$; for a given $u_{* \mathrm{c}} / u_{b}$, lower the $\varphi_{c w}$, larger is the $S / u^{2}{ }_{b} \kappa$. In [29], You also mentioned that $S / u^{2}{ }_{b} \mathcal{K}$ can be a linear function of $u_{* c} / u_{b}$, however, You [29] only discussed the cases of currents following the waves and opposing the waves. 
The appropriate values of $S$ from Equation (38) depend on the precision of the chosen reference current velocity $\bar{u}_{r}$ and on the assumed eddy viscosity in Equation (30). To obtain the empirical expression for the gradient $S$ with an arbitrary $\varphi_{c w}$, an angle-dependent correction factor $\gamma=1+2.1 \cos \varphi_{c w}$ is introduced. As shown in Figure $9 \mathrm{~b}$, the gradient $S$ in which $0^{\circ} \leq \varphi_{c w} \leq 90^{\circ}$ can be expressed as:

$$
S=\gamma \kappa u^{2}{ }_{b}\left(0.002 \frac{u_{* \mathrm{c}}}{u_{b}}+0.00003\right)
$$
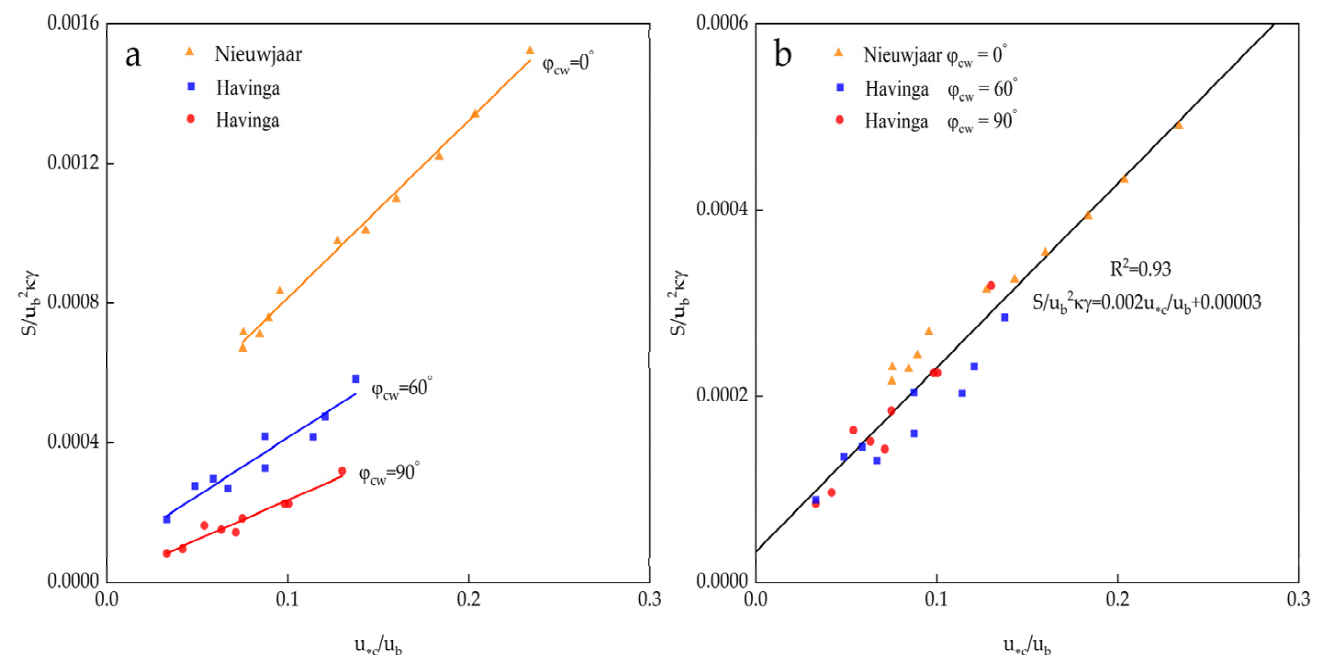

Figure 9. Gradient $S$ evaluated from Equation (21) in lab experiments of van der Kaaij and Nieuwjaar [44] and Havinga [46]. (a) $S / u^{2}{ }_{b} \kappa$ as a function of $u_{* \mathrm{c}} / u_{b} ;$ (b) $S / u^{2}{ }_{b} \kappa \gamma$ as a function of $u_{* \mathrm{c}} / u_{b}$.

\section{Conclusions}

In order to improve the shortcomings of the classical eddy viscosity models, a new semi-empirical 1DV model is proposed in this study. Based on the two-dimensional NavierStokes equations and new assumed wave and current eddy viscosities, the present model can calculate the mean current profiles by a top-to-bottom sequence. The present model is in good agreement with available laboratory experimental measurements and the present model is significantly more accurate than the previous eddy viscosity model SG2017.

By the comparison with the measured values of the thickness of the wave boundary layer, an accurate empirical formula for predicting the wave boundary layer thickness was derived. In the present model, the thickness of the wave boundary layer is defined as the distance between the mean bed level and the level at which the velocity defect should be $2 \%$ of the free-stream wave orbital velocity $u_{b}$. In the presence of ripples, both the physical bed roughness and apparent bed roughness in case of $\eta / \lambda \geq 0.13$ and $\eta / \lambda<0.13$ can be calculated using two different empirical formulae separately.

Through the analysis of the present model calculation results and the laboratory measurements, the deviations of the mean current profiles in the near-surface layer $(z / h>0.6)$ were attributed to the wave-induced second-order shear stress $-S z$. These deviations decrease as the intensity of the wave relative to the current decreases and the angle between the wave and current increases. In addition to the above factors, the size of the ripples was found to influence $S$, that is, when the ripple steepness and other conditions are almost the same, the higher the ripples, the larger values of the gradient $S$. The gradient $S$ of the waveinduced shear stress can be represented as a function of the wave parameters, the current strength, and the angle between the wave and current. Moreover, an angle-dependent correction factor $\gamma$ was introduced that allows the values of $S$ to be calculated using an empirical formula with an arbitrary angle between the wave and current.

The variables used in this paper are shown in Table 5. 
Table 5. List of variables.

\begin{tabular}{|c|c|c|c|c|c|}
\hline$A$ & $\begin{array}{l}\text { Ratio of velocity defect to } \\
\text { free-stream wave orbital } \\
\text { velocity }\end{array}$ & $A_{b}$ & Semi-excursion amplitude & $B$ & $\begin{array}{l}\text { Empirical coefficients } \\
\text { related to the thickness of } \\
\text { WBL }\end{array}$ \\
\hline$C_{R}$ & $\begin{array}{l}\text { A parameter that indicates } \\
\text { the enhancement of the } \\
\text { currents by waves. }\end{array}$ & $d$ & Index of agreement & $f_{w}$ & Wave friction factor \\
\hline$g$ & Gravitational acceleration & $h$ & Water depth & $H$ & Wave height \\
\hline$k$ & Wave number & $k_{a}$ & Apparent bed roughness & $k_{b}$ & $\begin{array}{l}\text { Bed roughness in the } \\
\text { presence of waves over } \\
\text { ripple beds }\end{array}$ \\
\hline$K_{c}$ & Current eddy viscosity & $k_{s}$ & Physical bed roughness & $K_{w}$ & Wave eddy viscosity \\
\hline$m$ & Scaling parameter & $M A E$ & Mean absolute error & $M A P E$ & $\begin{array}{l}\text { Mean absolute percentage } \\
\text { error }\end{array}$ \\
\hline RMSE & Root-mean-square error & $N$ & Number of waves & $\bar{P}$ & Time-averaged pressure \\
\hline$-S z$ & $\begin{array}{l}\text { Wave-induced second-order } \\
\text { stress }\end{array}$ & $S$ & $\begin{array}{l}\text { Gradient of wave-induced } \\
\text { second-order stress }\end{array}$ & $S_{1}$ & Gradient of radiant stress \\
\hline$S_{2}$ & $\begin{array}{l}\text { Gradient of the wave } \\
\text { Reynolds stress }\end{array}$ & $T$ & Wave period & $u$ & $\begin{array}{l}\text { Instantaneous horizontal } \\
\text { velocity }\end{array}$ \\
\hline $\bar{u}$ & Mean horizontal velocity & $\widetilde{u}$ & Periodic horizontal velocity & $u_{b}$ & $\begin{array}{l}\text { Free-stream wave orbital } \\
\text { velocity }\end{array}$ \\
\hline$u_{c}$ & Mean current velocity & $\bar{u}_{r}$ & Reference current velocity & $u_{* \mathrm{c}}$ & Current shear velocity. \\
\hline$u_{* w m}$ & Wave shear velocity & $u_{* c w}$ & $\begin{array}{l}\text { Characteristic shear velocity } \\
\text { within the WBL }\end{array}$ & WBL & Wave boundary layer \\
\hline$x_{i}^{c}$ & The calculated value & $x_{i}^{m}$ & $\begin{array}{l}\text { Values estimated from the } \\
\text { mean current profiles } \\
\text { measured in laboratory } \\
\text { experiments }\end{array}$ & $\bar{x}$ & The average of $x_{i}^{m}$ \\
\hline$z_{0}$ & $\begin{array}{l}\text { The height where velocity is } \\
\text { zero }\end{array}$ & $z_{0 a}$ & $\begin{array}{l}\text { Apparent hydraulic } \\
\text { roughness }\end{array}$ & $z_{r}$ & Reference height \\
\hline$z_{d}$ & $\begin{array}{l}\text { Level at which the current } \\
\text { velocities begin to decrease }\end{array}$ & $\bar{\tau}_{x z}$ & $\begin{array}{l}\text { Total shear force per unit } \\
\text { cross-sectional area }\end{array}$ & $\bar{\tau}_{0}$ & Mean bed shear stress \\
\hline$\tau_{w m}$ & $\begin{array}{l}\text { Maximum shear stress for } \\
\text { wave }\end{array}$ & $\Gamma_{w s}$ & Dimensionless wave shear & $\rho$ & Water density \\
\hline$\eta$ & Ripple height & $\bar{\eta}$ & Mean surface elevation & $\lambda$ & Ripple length \\
\hline$\delta$ & Thickness of WBL & $\delta_{1}$ & $\begin{array}{l}\text { Height of the transition } \\
\text { layer }\end{array}$ & $\beta$ & $=0.3$, an empirical coefficient \\
\hline$\kappa$ & =0.4, Von Kármán number & $\omega$ & Radian frequency & $\varphi_{c w}$ & $\begin{array}{l}\text { Angle between the mean } \\
\text { current and wave }\end{array}$ \\
\hline$\gamma$ & $\begin{array}{l}=1+2.1 \cos \varphi_{c w} \\
\text { angle-dependent correction } \\
\text { factor }\end{array}$ & & & & \\
\hline
\end{tabular}

Author Contributions: Data curation was performed by C.H., J.H. and Z.L.; writing-original draft preparation, C.H.; subsequent revisions of the manuscript were prepared by C.H. and J.H.; NSFC project management and funding were managed by J.H. All authors have read and agreed to the published version of the manuscript.

Funding: This work was supported by the Joint Funds of the National Natural Science Foundation of China (Grant No. U2040203).

Institutional Review Board Statement: Not applicable.

Informed Consent Statement: Not applicable.

Data Availability Statement: Not applicable.

Acknowledgments: The authors sincerely thank Chaofeng Tong, and Yuyang Shao for their guidance and assistance in selection of the thesis topic and derivation of equations. The reviewers' comments significantly contributed to improving the clarity of the manuscript.

Conflicts of Interest: The authors declare no conflict of interest. 


\section{References}

1. Pao, C.H.; Chen, J.L.; Su, S.F.; Huang, Y.-C.; Huang, W.-H.; Kuo, C.-H. The Effect of Wave-Induced Current and Coastal Structure on Sediment Transport at the Zengwen River Mouth. J. Mar. Sci. Eng. 2021, 9, 333. [CrossRef]

2. Mahmoodi, A.; Lashteh Neshaei, M.A.; Mansouri, A.; Bejestan, M.S. Study of current-and wave-induced sediment transport in the Nowshahr Port entrance channel by using numerical modeling and field measurements. J. Mar. Sci. Eng. 2020, 8, 284. [CrossRef]

3. Peng, Y.; Yu, Q.; Wang, Y.; Zhu, Q.; Wang, Y.P. Sensitivities of Bottom Stress Estimation to Sediment Stratification in a Tidal Coastal Bottom Boundary Layer. J. Mar. Sci. Eng. 2020, 8, 256. [CrossRef]

4. Kuang, C.; Han, X.; Zhang, J.; Zou, Q.; Dong, B. Morphodynamic Evolution of a Nourished Beach with Artificial Sandbars: Field Observations and Numerical Modeling. J. Mar. Sci. Eng. 2021, 9, 245. [CrossRef]

5. Ruggeri, A.; Musumeci, R.E.; Faraci, C. Wave-Current Flow and Vorticity Close to a Fixed Rippled Bed. J. Mar. Sci. Eng. 2020, 8, 867. [CrossRef]

6. Birrien, F.; Baldock, T. A Coupled Hydrodynamic-Equilibrium Type Beach Profile Evolution Model. J. Mar. Sci. Eng. 2021, 9, 353. [CrossRef]

7. Li, M.Z.; Amos, C.L. Sheet flow and large wave ripples under combined waves and currents: Field observations, model predictions and effects on boundary layer dynamics. Cont. Shelf Res. 1999, 19, 637-663. [CrossRef]

8. Nielsen, P. Coastal Bottom Boundary Layers and Sediment Transport; World Scientific: Singapore, 1992.

9. Van Rijn, L.C. Principles of Fluid Flow and Surface Waves in Rivers, Estuaries, Seas and Oceans; Aqua Publications: Amsterdam, The Netherlands, 1990.

10. Fredsøe, J.; Andersen, K.H.; Sumer, B.M. Wave plus current over a ripple-covered bed. Coast. Eng. 1999, 38, 177-221. [CrossRef]

11. Bakker, W.T.; Van Doorn, T. Near-bottom velocities in waves with a current. Coast. Eng. 1978, 1978, 1394-1413. [CrossRef]

12. Kemp, P.H.; Simons, R.R. The interaction between waves and a turbulent current: Waves propagating with the current. J. Fluid Mech. 1982, 116, 227-250. [CrossRef]

13. Mathisen, P.P.; Madsen, O.S. Waves and currents over a fixed rippled bed: 2. Bottom and apparent roughness experienced by currents in the presence of waves. J. Geophys. Res. Ocean. 1996, 101, 16543-16550. [CrossRef]

14. Grant, W.D.; Madsen, O.S. Combined wave and current interaction with a rough bottom. J. Geophys. Res. Ocean. 1979, 84, 1797-1808. [CrossRef]

15. Christoffersen, J.B.; Jonsson, I.G. Bed friction and dissipation in a combined current and wave motion. Ocean Eng. 1985, 12, 387-423. [CrossRef]

16. Styles, R.; Glenn, S.M. Modeling stratified wave and current bottom boundary layers on the continental shelf. J. Geophys. Res. 2000, 105, 24119-24139. [CrossRef]

17. Styles, R.; Glenn, S.M.; Brown, M.E. An Optimized Combined Wave and Current Bottom Boundary Layer Model for Arbitrary Bed Roughness; Coastal and Hydraulics Laboratory, US Army Engineer Research and Development Center: Vicksburg, MS, USA, 2017. Available online: https:/ / www.semanticscholar.org/paper/An-Optimized-Combined-Wave-and-Current-Bottom-LayerStyles-Glenn/48048be333db48df8f857d97162b8251b442e2af (accessed on 7 September 2021).

18. You, Z.J. Eddy viscosities and velocities in combined wave-current flows. Ocean Eng. 1994, 21, 81-97. [CrossRef]

19. Trowbridge, J.; Madsen, O.S. Turbulent wave boundary layers: 2. Second-order theory and mass transport. J. Geophys. Res. 1984, 89, 7999-8007. [CrossRef]

20. Foster, D.L.; Guenther, R.A.; Holman, R.A. An analytic solution to the wave bottom boundary layer governing equation under arbitrary wave forcing. Ocean Eng. 1999, 26, 595-623. [CrossRef]

21. Styles, R.; Bryant, D.B. Combined Wave and Current Bottom Boundary Layers: A Review; ERDC-CHL-SR-16-1; Army Engineer Research and Development Center: Vicksburg, MS, USA, 2016.

22. Davies, A.G.; Soulsby, R.L.; King, H.L. A numerical model of the combined wave and current bottom boundary layer. J. Geophys. Res. Ocean. 1988, 93, 491-508. [CrossRef]

23. Soulsby, R.L.; Hamm, L.; Klopman, G.; Myrhaug, D.; Simons, R.; Thomas, G. Wave-current interaction within and outside the bottom boundary layer. Coast. Eng. 1993, 21, 41-69. [CrossRef]

24. Shi, J.Z.; Wang, Y. The vertical structure of combined wave-current flow. Ocean Eng. 2008, 35, 174-181. [CrossRef]

25. Faraci, C.; Foti, E.; Musumeci, R.E. Waves plus currents at a right angle: The rippled bed case. J. Geophys. Res. Ocean. 2008, 113, C07018. [CrossRef]

26. Smaoui, H.; Kaidi, S. Bed Shear Stresses Parameterization in Wave-Current Interaction by k- $\omega$ Turbulence Model. Int. J. Appl. Mech. 2017, 9, 1750059. [CrossRef]

27. Zuo, L. Modelling and Analysis of Fine Sediment Transport in Wave-Current Bottom Boundary Layer; CRC Press: Boca Raton, FL, USA, 2018.

28. You, Z.J.; Wilkinson, D.L.; Nielsen, P. Velocity distributions of waves and currents in the combined flow. Coast. Eng. 1991, 15, 525-543. [CrossRef]

29. You, Z.J. The effect of wave-induced stress on current profiles. Ocean Eng. 1996, 23, 619-628. [CrossRef]

30. Sutherland, J.; Battjes, J.A. Wave Reynolds Stress and Its Effect on the Undertow Model. Master's Thesis, Technical University of Delft, Delft, The Netherlands, 1995. 
31. Peter, N.; You, Z.J. Eulerian mean velocities under non-breaking waves on horizontal bottoms. Proc. Coast. Eng. Conf. 1997, 4, 4066-4077. [CrossRef]

32. Longuet-Higgins, M.S. The mechanics of the boundary layer near the bottom in a progressive wave. In Proceedings of the 6th International Conference on Coastal Engineering; ASCE: Berkeley, CA, USA, 1958; Volume 184, p. 193.

33. Supharatid, S.; Tanaka, H.; Shuto, N. Interactions of waves and current (Part I: Experimental investigation). Coast. Eng. Jpn. 1992, 35, 167-186. [CrossRef]

34. Chun, H.; Suh, K.D. Wave-induced Reynolds stress in three-dimensional nearshore currents model. J. Coast. Res. 2016, 32, 898-910. [CrossRef]

35. Davies, A.G.; Villaret, C. Eulerian drift induced by progressive waves above rippled and very rough beds. J. Geophys. Res. Ocean. 1999, 104, 1465-1488. [CrossRef]

36. Van der, A.D.A. 1DV Modelling of Wave-Induced Sand Transport Processes over Rippled Beds. Master's Thesis, University of Twente, Enschede, The Netherlands, 2005.

37. Nielsen, P. 1DV structure of turbulent wave boundary layers. Coast. Eng. 2016, 112, 1-8. [CrossRef]

38. Grant, W.D.; Madsen, O.S. Movable bed roughness in unsteady oscillatory flow. J. Geophys. Res. Ocean. 1982, 87, 469-481. [CrossRef]

39. Salles, P.A.A. Eddy Viscosity Models for Pure Waves over Large Roughness Elements. Master's Thesis, Massachusetts Institute of Technology, Cambridge, MA, USA, 1997.

40. Sleath, J.F.A. Turbulent oscillatory flow over rough beds. J. Fluid Mech. 1987, 182, 369-409. [CrossRef]

41. Mathisen, P.P. Bottom Roughness for Wave and Current Boundary Layer Flows over a Rippled Bed. Ph.D. Thesis, Massachusetts Institute of Technology, Cambridge, MA, USA, 1993.

42. Barrantes, A.I. Turbulent boundary layer flow over two-dimensional bottom roughness elements. Ph.D. Thesis, Massachusetts Institute of Technology, Cambridge, MA, USA, 1997.

43. Rodríguez-Abudo, S.; Foster, D.L. Direct estimates of friction factors for a mobile rippled bed. J. Geophys. Res. Ocean. 2017, 122, 80-92. [CrossRef]

44. Van der Kaaij, T.H.; Nieuwjaar, M.W.C. Sediment Concentrations and Transport in Case of Irregular Non-Breaking Waves with a Current, Part A and B. Master's Thesis, Delft University of Technology, Delft, The Netherlands, 1987. Available online: https:/ / repository.tudelft.nl/islandora/object/uuid\%3Ac4267aec-cca1-4de8-bdb7-77e40a236829 (accessed on 7 September 2021).

45. Nap, E.; Van Kampen, A. Sediment Concentrations and Transport in Case of Irregular Non-Breaking Waves with a Current, Part A and B. Master's Thesis, Delft University of Technology, Delft, The Netherlands, 1988. Available online: https:/ /repository. tudelft.nl/islandora/object/uuid\%3Ad079b281-a758-440d-badc-4e41a848bca5 (accessed on 7 September 2021).

46. Havinga, F.J. Sediment Concentrations and Sediment Transport in Case of Irregular Non-Breaking Waves with a Current. Master's Thesis, Delft University of Technology, Delft, The Netherlands, 1992. Available online: https:/ / repository.tudelft.nl/islandora/ object/uuid:b57004ae-f32c-4083-8789-58788a55626a (accessed on 7 September 2021).

47. Mathisen, P.P.; Madsen, O.S. Waves and currents over a fixed rippled bed: 1 . Bottom roughness experienced by waves in the presence and absence of currents. J. Geophys. Res. Ocean. 1996, 101, 16533-16542. [CrossRef]

48. Van Rijn, L.C. Unified view of sediment transport by currents and waves. I: Initiation of motion, bed roughness, and bed-load transport. J. Hydraul. Eng. 2007, 133, 649-667. [CrossRef]

49. Sleath, J.F.A. Velocities and shear stresses in wave-current flows. J. Geophys. Res. Ocean. 1991, 96, 15237-15244. [CrossRef]

50. Willmott, C.J.; Feddema, J.J.; Klink, K.; LeGates, D.R.; O’Donnell, J.; Rowe, C.M. Statistics for the evaluation and comparison of models. J. Geophys. Res. Ocean. 1985, 90, 8995-9005. [CrossRef]

51. Madsen, O.S.; Salles, P. Eddy viscosity models for wave boundary layers. Coast. Eng. 1998, 26, 2615-2627. [CrossRef]

52. Bijker, E.W.; Kalkwijk, J.P.T.; Pieters, T. Mass Transport in Gravity Waves on a Sloping Bottom. Coast. Eng. Proc. 1974, 447-465. [CrossRef] 